\title{
Sediment core phosphorus and other human-influenced element distributions record historical land use and runoff changes in the watershed of an urban lake
}

\author{
STEPHANIE SLOWINSKI ${ }^{1}$, JOVANA RADOSAVLJEVIC ${ }^{1}$, \\ ALYSSA GRAHAM ${ }^{1}$, FEREIDOUN REZANEZHAD ${ }^{1}$, \\ MAHYAR SHAFII ${ }^{1}$, CHRISTOPHER PARSONS ${ }^{2}$, KATHRYN \\ THOMAS $^{3,4}$, JOHAN WIKLUND ${ }^{1}$, ROLAND HALL ${ }^{1}$ AND \\ PHILIPPE VAN CAPPELLEN ${ }^{1}$ \\ ${ }^{1}$ University of Waterloo \\ ${ }^{2}$ Environment and Climate Change Canada, Canada Centre for \\ Inland Waters \\ ${ }^{3}$ Ontario Tech University \\ ${ }^{4}$ Stillwater Environmental \\ Presenting Author: seslowin@uwaterloo.ca
}

Urbanization is an important modifier of nutrient and contaminant inputs to aquatic environments due to increases in anthropogenic sources in urban areas compared to rural land use types, and due to the increase in impervious area and runoff potential. Lake Wilcox is a natural kettle lake in the greater Toronto metropolitan area whose watershed has progressively become more sub-urban and urban since the 1940s, resulting in increased eutrophic conditions within the lake. Initial management in the 1980s focussed on replacing septic tank usage by expanding the city sewage system, whereas more targeted management efforts within the lake and watershed began in the 1990s. To assess the impact of land use changes on the loadings of the limiting nutrient phosphorus (P) and other elements to the lake, we collected a $76 \mathrm{~cm}$-long sediment core. Radioisotope dating indicates that the deepest sediments of the core were deposited around 1920 . For each $1 \mathrm{~cm}$ core segment, we measured the total $1 \mathrm{M} \mathrm{HCl}$-extractable $\mathrm{P}, \mathrm{Fe}, \mathrm{S}, \mathrm{Mn}, \mathrm{Na}, \mathrm{K}$ and $\mathrm{Al}$, along with organic carbon, nitrogen and sulfur content. We also extracted a subset of the core samples using a sequential extraction procedure that differentiates the various sediment $\mathrm{P}$ pools, including the redox-labile, humic-bound, organic, and exchangeable $\mathrm{P}$. The increase in eutrophication, including the influence of septic system discharge by cottages along the lakeshore, are clearly marked by an increase in total and organic $\mathrm{P}$ concentrations with time. Total $\mathrm{Na}$ concentrations also record the increase in urban land coverage in the watershed, which have been increasing since the 1960 s coincident with regional road salt application trends. Distinct changes in the depth distributions of $\mathrm{HCl}$-extractable $\mathrm{S}$ and $\mathrm{Fe}$ are attributed to atmospheric deposition in the watershed originating from a nearby coal burning power plant until it was decommissioned in the mid2000s. Ongoing work is coupling the historical changes in sediment burial rates of $\mathrm{P}$ (and other elements) to the changes in the lake's biogeochemical P cycling and biological productivity that accompanied the rural to urban land use transition of the watershed. 